\title{
REVIEW ON CORBONDIOXIDE CURING OF CONCRETE
}

\author{
Dr.Vijaya Kumar Y.M \\ M-Tech, Ph.D \\ Department of Civil Engineering \\ AIT, Chikkamagalur, Karnataka, India
}

\author{
Seema B S \\ Assistant Professor \\ Department of Civil Engineering \\ AIT, Chikkamagalur, Karnataka, India
}

\begin{abstract}
Carbon dioxide (CO2) is the reason of increasing the global warming resulting from human industrial activities, to reduce these emissions of $\mathrm{CO} 2$ there is a necessity for sequestration of $\mathrm{CO2}$ into stable forms. The paper summarizes the mechanical properties of concrete when cured on $\mathrm{CO} 2$ that is by using $\mathrm{CO} 2$ chamber. The research includes designing a concrete mix of M25 and M30 grade as per IS 10262:2009. The experimental study on water cured and $\mathrm{CO} 2$ specimens for compression strength were carried out. The results show that for M25 and M30 grade of concrete has achieved increasing value as comparing with 7days of water curing and the duration of 4hour $\mathrm{CO} 2$ curing. For M25 grade of concrete has achieved $70 \%$ of compression strength and M30 grade of concrete has achieved $65 \%$ of compression strength in the duration of 4hours of $\mathrm{CO} 2$ cured specimens when compared to 28days of water cured specimens.
\end{abstract}

Keywords: Concrete, CO2, Compression strength Carbonation.

\section{INTRODUCTION}

Curing process is essential if concrete is to do arranged limit in excess of the structure life of the strong structure. If the over the top reestablishing time may incite the speeding up of the advancement cost of the undertaking and trivial interruptions. Anywhere there is an absence of water is more and the spot of slanting exteriors anywhere calming by water is hard and circumstances wherever there is a huge areas.

Curing is the help of an attractive soddenness substance and temperature in concrete for some time rapidly putting and finishing with the objective that the perfect things may make in the during of hydration. In order to accomplish a not too bad quality of concrete, a proper mix must be trailed by diminishing in a sensible area during the starting periods of hardening. Reestablishing must be endeavored for an important time span if the concrete is to get its conceivable quality then toughness.

\section{LITRATURE REVIEW}

T. Santhosh Kumar et al (2019) [1], they have studied the $\mathrm{CO} 2$ cured concrete mechanical properties. They are experimented by dry ice and $\mathrm{CO} 2$ cured blocks by using the compressive strength, split tensile and flexural Value were conceded out for 4,6,8 hours. The experimental study on water cured, $\mathrm{CO}_{2}$ cured and dry ice cured specimens for compressive strength, split tensile strength and flexural strength were carried out. The outcomes show that $90 \%$ of compressive strength, $89 \%$ of flexural strength and $92 \%$ of tensile strength was achieved, comparing with 28days water cured blocks and 8 hours of $\mathrm{CO} 2$ cured blocks.

Rakesh d r. kavitha et al., (2018) [2], They have studied use of co 2 mitigation responses in concrete and cement products is one of the possible technologies as carbon sink through the fast curing in early age, used bamboo fibre was a replaced material for cement as $1 \%$ with the water cement ratio was 0.53. in order to find out the Carbonation curing, they comparing with fiber and without fiber. They have tested both water curing and carbon curing for 3,7,14.21.28 days, finally they have got more strength in with fiber used specimen and also get more strength in $\mathrm{CO} 2$ cured specimen when comparing conventional cured specimen.

Ming-Gin Lee et al., (2017) [3], this paper summarized the $\mathrm{CO} 2$ cured cylinder with 3 different sizes and the compressive strength with various curing timings and finally compared with 28 days of water cured cylinder with different sizes. The results of $\mathrm{CO} 2$ cured concrete ratio or longer $\mathrm{CO} 2$ curing time produced higher early strength. The concrete specimen mixed with $\mathrm{CO} 2$ under 0.2 to $0.6 \mathrm{Mpa}$ pressure produced lower compressive strength the results show like cylinder has got higher compressive strength when comparing conventional cured blocks.

D.Gowsika, et al., (2017) [4], they have concentrated to assess viability of various curing methods and study the impact of atmosphere on the quality properties of cement. The examples were thrown for the testing of compressive quality at 7,14 and 28 days of relieving. Individually they were utilizing seven restoring techniques, to be specific Ponding, Immersion, Oven relieving, Air Drying, calcium chloride (random), Membrane relieving and Pack (Plastic sheeting) restoring. Test outcomes demonstrate that water restoring quality was improved up to $26.67 \%$ than film and shows $93 \%$ of 


\section{International Journal of Engineering Applied Sciences and Technology, 2021 \\ Vol. 5, Issue 10, ISSN No. 2455-2143, Pages 171-174 \\ Published Online February 2021 in IJEAST (http://www.ijeast.com)}

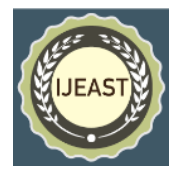

traditional relieving. All through this investigation it is done over the solid has enormous impact on its quality properties on various techniques for restoring.

Hilal El-Hassan et al., (2015) [5], they Studied the method of carbon curing he found that it will successively replace steam curing by its unique advantages like accelerated the hydration. Comparing the method of $\mathrm{CO} 2$ and stream got the result like increasing the hydration.

Macmaster. Oscar Tavares et al., (2015) [6], they have considered that compute the carbon allocation levels in concrete by making different relieving procedures. An extraordinary $\mathrm{CO} 2$ relieving chamber was orchestrated to empower speeding up response by the utilization of carbon sequestration. They have arranged $\mathrm{CO} 2$ restoring chamber with a thermocouple and vacuum framework are given, thermocouples is only for watching temperature, dampness and weight. Tests were thrown and relieved in $\mathrm{CO} 2$ restoring chamber for 2 hours as it were. At first, tests were contrasted and conventional oven restored examples at $100 \% \mathrm{CO} 2$ and at the weight was 20 psi. In this time of relieving time ( 2 hours). Ceaseless examination of comparative moistness, temperature and weight expansion were achieved. At 2-hours of $\mathrm{CO} 2$ relieving, the most extreme temperature was reached to $30^{\circ} \mathrm{C}$ from $18.9^{\circ} \mathrm{C}$ and stayed consistent till the end. The virtual moistness arrived at a greatest at the beginning of the relieving test and diminished at $30 \mathrm{~min}$ and increment following $30 \mathrm{~min}$ till the finish of 2 hour.

ZhanBaojian et al., (2013) [7], they have developed blocks using recycled aggregate. Located in a pressed $100 \%$ of Curing chamber for 6 and the 12 after those 14 hours, meanwhile he conducted experiment on the moisture cured blocks also. Initial and final relative humidity and temperature were noted. He measured the strength. Outcome of experiment should that $\mathrm{CO}_{2}$ cured block have got high compressive strength was compared to moisture cured block.

Caijun shi faqiang yanzhong wu et al., (2011) [8], They have used shale as a light weight aggregate then they have compare with steam curing and $\mathrm{CO} 2$ with the pressure of $\mathrm{CO} 2$ is 10 and 20psi steam curing is $70 \mathrm{c}$ they have conducting the experiments with different preconditioning, finally they have got $\mathrm{CO} 2$ curing is more strength with the short time duration, it takes only 4hours and steam curing time is 20 and more. $\mathrm{CO} 2$ cured specimen's moisture loss were more May results in terrible of the cubes.

Y. Shao et al., (2010) [9], this paper summed up that the achievability of utilizing reused $\mathrm{CO} 2$ in solid squares through the relieving procedure. This kind of relieving process is conveyed to two different ways one is Open-gulf framework and shut channel framework utilizing pressurized pipe gas of low fixation. Precast examples were relieved in the chamber, in open-delta framework $\mathrm{CO} 2$ gas with great virtue is approved into the shut chamber at a weight of 21 pound square inches and in a shut framework vent gas comprising $14 \%$ of $\mathrm{CO} 2$ is passed at a weight of 72 psi. The $\mathrm{CO} 2$ gas was passed in 7 cycles with a time span of 30 to $40 \mathrm{~min}$. The outcomes shows that the solid items relieved in $\mathrm{CO} 2$ show's superior outcomes for mechanical properties.

Vibhas Bamboo et al., (2010) [10], they have Conducted test research to discover the ingestion of $\mathrm{CO} 2$ in solid shafts. For this situation a metallic relieving chamber was set up with the vent and channel regulators. A weight measure was connected to the weight privileged the chamber. The examples were thrown and set in $\mathrm{CO} 2$ relieving chamber for 4 hours and 8 hours. What's more, they were contrasted and the examples in a customary technique for the 28 days. After 4 hours and 8 hours of $\mathrm{CO} 2$ restored tests are tried, the compressive quality was show to increment by $12.3 \%$ and $27.7 \%$ and for 8 hours of $\mathrm{CO} 2$ relieving the flexural quality was appeared to increment by $1.8 \%$ than tests restored in water.

Teramura et al., [2000] [11], they have used ALC as clasp in the $\mathrm{CO} 2$ development. The excess ALC were sieved by 1.8 $\mathrm{mm}$ and a short time later handled by a ball-plant for sixty min. The liquid to solid extent was in the extent of 25 to $65 \%$ by the weight. The wet excess ALC was compressed in the shape under 10MPa strain to outline the plate $100 \mathrm{~mm} \times 100 \mathrm{~mm}$ x $12 \mathrm{~mm}$. This technique they were used $100 \%$ centralization of $\mathrm{CO} 2$ and gas force from air to $0.4 \mathrm{MPa}$. They in like manner test air carbonation by using 3\% $\mathrm{CO} 2$ obsession and 3\% of pneumatic stress. The carbonated models were drying in an oven at $60^{\circ} \mathrm{C}$ for the duration of 24 hours afterward carbonation. Three-point bowing test were used for those plates and the cross-head pace of $0.2 \mathrm{~mm} / \mathrm{min}$.

Simatupang et al., [1995] [12], they have advanced a industrialized method for cement particle boards in order to decrease the pressing duration. Wood elements were saturated in the water, then additional to Portland cement and mixed well. Different stainless steel equipment was used to do quick $\mathrm{CO} 2$ curing. The press sleeve to take up the moist wood/cement mixture and the piston to condense the mortar. The compaction pressure was $4 \mathrm{MPa}$. Press plate used for $\mathrm{CO} 2$ was injected top and bottom into the specimen. The w/c ratio was varied. And that is from 0.1-0.6, account the water. Better results were obtained.

Bukowski et al., [1978] [13], they have tried of University was used the $\mathrm{C} 2 \mathrm{~S}, \mathrm{CS}$ and Portland concrete as clasp to examine $\mathrm{CO} 2$ gas soothing. The extent of clasp to sand was composed by weight, and the extent of water to sheet was by mass was $0.202,0.206$ and 0.191 for C2S, CS and ordinary concrete, independently. They have used hand mixing for nearly $3 \mathrm{~min}$ and a while later trodden at $26 \mathrm{MPa}$ load into $15.9 \mathrm{~mm}$ in expansiveness loads around $20 \mathrm{~mm}$ height. After 


\section{International Journal of Engineering Applied Sciences and Technology, 2021 \\ Vol. 5, Issue 10, ISSN No. 2455-2143, Pages 171-174 \\ Published Online February 2021 in IJEAST (http://www.ijeast.com)}

compaction was done, the chamber was kept in a container by $95 \%$ relative tenacity for 2 hours earlier carbonation. They have furthermore used calcium silicate powders for carbonation with a comparable water and cement extent as the preservationist mortars.

\section{WATER CURING}

Prerna Tighare et al., (2017) [14], This paper says that in the wake of experiencing the current writing on Contrast of impact of Hot water relieving, steam restoring and Usual restoring on quality of M20 evaluation of cement there is certain weakness of submersion strategy and to conquer this inadequacies the current exploration exertion targets considering the blend of inundation technique and different strategies for relieving like jute pack covering technique and plastic film technique. The exertion will be ready to recreate the ground condition in lab. The examination looks to evaluate the impact of various restoring techniques on compressive quality of cement and cement ought to be relieved by best restoring strategy to accomplish a superior compressive quality. The current examination targets joining inundation strategy with damp covering, with utilization of restoring compound and plastic sheeting water prerequisite for 7 days, for example submersion relieving joined with these is proposed to be determined.

Ajay Goel, Jyoti Narwal, et al., (2013) [15], The normal compressive quality of cement at various ages for example 3 , 7, 28 and 56 days affected by three sorts of restoring techniques specifically air, plastic film and relieving by Water relieving is more quality when looking at all three kinds relieving.

Dr K. V Krishna Reddy et al., (2013) [16], this investigation to assess viability of various restoring strategies and study the impact of atmosphere on the quality properties of cement. Diverse restoring strategies in particular ponding, jute sack relieving, single layered film restoring, twofold layered layer restoring and air restoring are considered to examine the impact of various techniques for relieving and atmosphere on the nature of cement. Solid examples were tried subsequent to restoring of 3 days, 7 days and 28 days. Relieving compound was showered following expulsion from moulds and in the event of the twofold coat the subsequent coat was applied after 5 min of utilization of first coat. Standard Portland concrete of 53 evaluations fulfilling the prerequisites of IS: 12269-1987 with 28-days compressive quality of $58.5 \mathrm{Mpa}$ is utilized. Blend configuration was finished focusing on M60 grade concrete according to ACI guidelines. Restoring might be applied in countless behaviour and the most fitting methods for sacking might be absorbed by the place or the growth technique. Result got the expansion in quality up to 85 to $90 \%$ of ponding.
T. James et al (2011) [17], This examination reports the all out of 72 3D shapes of blend proportion 1:2:4 were explored subsequent to exposing them to different relieving circumstances, the outcomes acquired validated ordinary compressive eminence qualities for 7, 14, 21 and 28 days, shift with restoring techniques, the outcomes show that ponding had the most raised compressive excellence and the its thickness.

\section{CONCLUSION}

After studying the journal papers, many researchers as said that the outcomes from the exploratory investigation considering for assessing the mechanical properties of example relieved in the water and $\mathrm{CO} 2$. The $\mathrm{CO} 2$ restored examples accomplished early quality when contrasted with water relieved.

\section{ACKNOWLEDGEMENT}

We are thank full to our beloved Principal and management of AIT Chikkamagaluru for support extended throughout the work. I also thank all those who directly or indirectly assisted in the successful completion of paper.

\section{REFERENCES}

[1] Bukowski, J.M. and Berger R.L. (1979), "Reactivity and Strength Development of Activated Non-Hydraulic Calcium Silicates", Cement and Concrete Research. Vol.9, pp57-68.

[2] Simatupang, M.H. and Habighorst, C. (1995), Investigations on the Influence of the Addition of Carbon Dioxide on the Production and Properties of Rapidly Set Wood- Cement Composites, Cement \& Concrete Composites, 17, pp 187-197.

[3] Teramura, S. and Isu, N. (Nov.2000), "New Building Material from Waste Concrete by Carbonation", Journal of Materials in Civil Engineering, pp288-293.

[4] Rostami, V., Shao, Y. and Boyd, A. (2012) Carbonation curing versus steam curing for precast concrete production, Journal of Materials in Civil Engineering, 24(9), 1221-1229.

[5] ZhanBaojian ${ }^{\text {a }}$ PoonChisun $^{\text {a }}$ ShiCaijun $^{\text {b }} 2013$ " CO $_{2}$ curing for improving the properties of concrete blocks containing recycled aggregates" Cement and Concrete Composites Volume 42, September 2013, Pages 1-8.

[6] Hilal El-Hassan and Yixin Shao 2015 "Early carbonation curing of concrete masonry units with Portland limestone Cement and Concrete Composites" Volume 62, September 2015, Pages 168-177. 
[7] T.James 2011 "effect of curing method on the highest compressive strength of concrete" Nigerian journal of technology Vol.30, no.3, October 2011.

[8] T. Santhosh kumar 2019 mechanical properties of concrete when cured with carbon ISSN: 2249-8958, Vol-8 Issue-6, August 2019.

[9] Rakesh DR, kavitha et al [2018], "CO2 uptake in bamboo fiber reinforced concrete under carbonation curing", volume 1.

[10] Caijun Shi Fuqiang He et al [2011] "Effect of preconditioning on $\mathrm{CO} 2$ curing of lightweight concrete blocks mixture" Construction and Building Materials.

[11] D.Gowsika, 2P.Balamurugan et al [2017] "Experimental Study on Curing Methods of Concrete" Volume 5, Issue 1 ISSN: 2321-9939

[12] Ajay Goel, Jyoti Narwal, Vivek Verma,et al [2013], “A Comparative Study on the Effect of Curing on The Strength of Concrete" ISSN: 2249 - 8958, Volume-2, Issue-6,

[13] Vibhas Bambroo, Shipali Gupta, Pratik Bhoite, S.K.Sekar "Study on the potential of carbon dioxide absorption in reinforced concrete beams", Material Science and Engineering, vol-263 032033, 2017.

[14] Ming-Gin Lee, Yung-Chih Wang, Yu-Min SU, YuCheng Kan, and Shih-Hsuan Kao "Effect of Cylinder Size on the Compressive Strength of Concrete CO2 Curing", Sustainability and climate, Sustainable Civil Infrastructures 2017.

[15] Don MacMaster and Oscar Tavares "Carbon Sequestration of Concrete Masonry Units", ACI materials journal, Vol-112, No. 6, December 2015.

[16] Y Shao, S. Moknam, A. J. Boyd "Recycling carbon dioxide into concrete: a feasibility study", International Concrete Sustainability Conference, National Ready Mixed Concrete Association, January 2010

[17] Prerna Tighare "Comparison of Effect of Hot Water Curing, Steam Curing \& Normal Curing on Strength of M20Grade of Concrete" Volume 5 Issue V, May 2017.

IC Value: 45.98 ISSN: 2321-9653

[18] Krishna Rao, M V, Rathish Kumar, \&P, Azhar Khan, M 2010, 'A study on the influence of curing on the strength of a standard grade concrete mix'

Architecture and Civil Engineering,Vol. 8, No 1, pp. 23 - 34

[19] ACI Committee 612, "curing of concrete", journal of American concrete institute, vol. 30, No.2, August, 1958, pp.161-172.

[20] J. Monkman and A. J. Boyd (Recycling Carbon Dioxide into Concrete: A Feasibility Study-Berger, R. L., Young, J. F., and Leung, K. 1972. Acceleration of hydration of calcium silicates by carbon-dioxide treatment. Nature: Physical Science, 240: 16-18.)

[21] Kou Shi-Cong, Zhan Bao-jian, Poon Chi-Sun (Use of a CO2 as curing agent- Department of Civil and Environmental Engineering, The Hong Kong Polytechnic University, Hong Kong, Cement \& Concrete Composites 45 (2014) 22-28 